\title{
BMJ Open Evaluating Montréal's harm reduction interventions for people who inject drugs: protocol for observational study and cost-effectiveness analysis
}

\author{
Dimitra Panagiotoglou (D) , ${ }^{1}$ Michal Abrahamowicz, ${ }^{1,2}$ David L Buckeridge, ${ }^{1,3}$ \\ J Jaime Caro, ${ }^{1,4,5}$ Eric Latimer, ${ }^{6,7}$ Mathieu Maheu-Giroux, ${ }^{1}$ Erin C Strumpf ${ }^{1,8}$
}

To cite: Panagiotoglou D, Abrahamowicz M, Buckeridge DL, et al. Evaluating Montréal's harm reduction interventions for people who inject drugs: protocol for observational study and cost-effectiveness analysis. BMJ Open 2021;11:e053191. doi:10.1136/ bmjopen-2021-053191

- Prepublication history for this paper is available online. To view these files, please visit the journal online (http://dx.doi org/10.1136/bmjopen-2021053191).

Received 06 May 2021 Accepted 07 October 2021

Deck for updates

(c) Author(s) (or their employer(s)) 2021. Re-use permitted under CC BY-NC. No commercial re-use. See rights and permissions. Published by BMJ.

For numbered affiliations see end of article.

\section{Correspondence to} Dimitra Panagiotoglou; dimitra.panagiotoglou@mcgill. ca

\section{ABSTRACT}

Introduction The main harm reduction interventions for people who inject drugs (PWID) are supervised injection facilities, needle and syringe programmes and opioid agonist treatment. Current evidence supporting their implementation and operation underestimates their usefulness by excluding skin, soft tissue and vascular infections (SSTVIs) and anoxic/toxicity-related brain injury from cost-effectiveness analyses (CEA). Our goal is to conduct a comprehensive CEA of harm reduction interventions in a setting with a large, dispersed, heterogeneous population of PWID, and include prevention of SSTVIs and anoxic/toxicity-related brain injury as measures of benefit in addition to HIV, hepatitis $\mathrm{C}$ and overdose morbidity and mortalities averted.

Methods and analysis This protocol describes how we will develop an open, retrospective cohort of adult PWID living in Québec between 1 January 2009 and 31 December 2020 using administrative health record data. By complementing this data with non-linkable paramedic dispatch records, regional monthly needle and syringe dispensation counts and repeated cross-sectional biobehavioural surveys, we will estimate the hazards of occurrence and the impact of Montréal's harm reduction interventions on the incidence of drug-use-related injuries, infections and deaths. We will synthesise results from our empirical analyses with published evidence to simulate infections and injuries in a hypothetical population of PWID in Montréal under different intervention scenarios including current levels of use and scale-up, and assess the cost-effectiveness of each intervention from the public healthcare payer's perspective.

Ethics and dissemination This study was approved by McGill University's Institutional Review Board (Study Number: A08-E53-19B). We will work with community partners to disseminate results to the public and scientific community via scientific conferences, a publicly accessible report, op-ed articles and open access peer-reviewed journals.

\section{INTRODUCTION}

Harm reduction interventions for people who inject drugs (PWID) are public health services designed to mitigate the negative physical and social consequences of injection
Strengths and limitations of this study

- This will be a comprehensive cost-effectiveness analysis of harm reduction interventions in a setting with a large, dispersed, heterogeneous population of people who inject drugs (PWID).

- The study will use a variety of data (administrative health records, paramedic dispatches, needle and syringe dispensations, and biobehavioural surveys) and analytical methods (eg, interrupted time series, mathematical models, marginal structural Cox models, and Poisson regressions) to estimate local effects of harm reduction interventions.

- The cost-effectiveness analysis takes account of standard and novel drug-use-related injuries and infections (ie, overdose; anoxic/toxicity-related brain injury; skin, soft tissue, and vascular infections; HIV; hepatitis $\mathrm{C}$ and death) as health outcomes.

- Clinician experts and patient-partners will review our simulation model to ensure accurate representation of pathways PWID can encounter.

- The study relies on administrative data to identify PWID thereby limiting the cohort to individuals who engage with the healthcare system (ie, most severe cases), possibly reducing the generalisability of the results.

drug use. Three common interventions are supervised injection facilities (SIF), needle and syringe programmes (NSP) and opioid agonist treatment (OAT). ${ }^{1}$

While there is considerable evidence that SIFs, NSPs and OAT help mitigate morbidity and mortality from overdoses, HIV and hepatitis $\mathrm{C}(\mathrm{HCV})$, these interventions remain politically controversial. ${ }^{2-8}$ Critical gaps in the literature contribute to the underrating of these harm reduction interventions as crucial health services. For starters, much of the available research is specific to the concentrated epidemics of Vancouver's Downtown Eastside and Sydney's 'red light' district. ${ }^{5}$ This leaves the effects of 
interventions unclear in contexts where the population is diffuse (ie, geographically scattered), the drug use scene is not dominated by opioids, and interventions are being scaled-up (eg, SIFs implemented but not used at capacity immediately)..$^{9} 10$

The paucity of epidemiological studies on substance use sequelae and the effects of harm reduction interventions on these sequelae underestimates the usefulness of SIFs, NSPs and OAT. Despite skin, soft tissue and vascular infections (SSTVIs) including endocarditis, bacteremia, sepsis and osteomyelitis being the most common reasons for hospital admissions among PWID, ${ }^{11}{ }^{12}$ studies on the effects of harm reduction interventions on SSTVIs are sparse. This is a critical oversight considering the estimated prevalence among PWID is $10 \%-30 \%$, and the nontrivial morbidity and mortality risks of SSTVIs. ${ }^{13} 14$ Complications from delayed care of infections can result in adverse outcomes such as surgical debridement, limb amputation, renal failure and death. ${ }^{15-17}$ Similarly, while physicians report an increase in anoxic/toxicity-related brain injury following severe opioid-related overdose (ie, cessation of breathing, hypoxia), ${ }^{18} 19$ a review of the literature published on Medline found a single study of 10 cases in Melbourne (Australia) describing the long-term consequences of hypoxia on brain health following heroin overdose ${ }^{20}$ another estimating the prevalence among heroin users in Oslo (Norway) using forensics data ${ }^{21}$ and most recently a paper from Shaanxi (China) linking brain white matter integrity with heroin relapse. Instead, research has focused on identifying risk factors associated with repeat overdoses or quantifying the burden of overdose visits on health services. ${ }^{22}{ }^{23}$ Neglecting to include these sequelae in evaluations of harm reduction interventions makes it impossible to properly assess, compare and prioritise strategies.

Our goal is to conduct a comprehensive costeffectiveness analysis (CEA) of harm reduction interventions for PWID in Montréal, Canada. To do so, we will:

1. Estimate the effects of SIFs, NSPs, OAT, paramedic naloxone use, and the Good Samaritan Drug Overdose Act (henceforth 'interventions') on the incidence of druguse-related injuries/infections (ie, overdose, anoxic/ toxicity-related brain injury, SSTVIs, HIV and HCV) and death.

2. Determine the direct costs of treating the sequelae, and providing the interventions from the healthcare payer's perspective.

3. Evaluate, from the point of view of the public healthcare payer: :

a. The cost-effectivness of interventions together, compared with no harm reduction service delivery.

b. The relative cost-effectiveness of interventions compared with each other.

c. The impact of full scale-up of each intervention and adoption by the community.
METHODS AND ANALYSIS

\section{Project start and end dates}

This project begins August 2021 and ends September 2025.

\section{Study setting}

Montréal, Canada has one of the country's largest PWID populations with approximately $1.3 \%$ of adults (95\% CI: $1.0 \%$ to $1.7 \%$ ) reporting having injected drugs at least once in the past, and approximately $0.2 \% \quad(n=4000,95 \%$ CI: 3180 to 4900 ) currently injecting drugs. ${ }^{24}$

The city has a long history of providing harm reduction services, bolstered by recent federal and provincial policies. Fixed site and mobile NSPs have existed since 1989. ${ }^{25}$ In 2017, four of these service providers (Cactus, Dopamine, Spectre de rue and L'Anonyme), in collaboration with regional health authorities, began operating the only SIFs in the province. ${ }^{26}$ Montréal paramedics began carrying naloxone to reverse opioid-related overdoses in July 2014, with full scale-up realised in $2017 .{ }^{27}$ Furthermore, Québec residents are mandated to enrol in the Public Prescription Drug Insurance Plan unless privately insured, and the provincial insurance programme ensures access to critical pharmaceuticals at little or no cost, regardless of public or private insurance coverage. ${ }^{28} 29$ This includes access to OAT and naloxone for opioid addiction and overdose, antiretrovirals and pre-exposure prophylaxis for HIV, ${ }^{30-32}$ and direct acting antivirals for HCV. ${ }^{233}$ Meanwhile, the federal government's Good Samaritan Drug Overdose Act of 2017 encourages 9-1-1 calls by providing legal protection (eg, from charges of possession) to individuals seeking emergency help during an overdose. ${ }^{35}$

The proportion of persons who inject daily in Montréal remains high, ${ }^{36}$ the most recent available HCV incidence is stable (9.2 and 7.8 per 100 person-years for 2016 and 2017, respectively), ${ }^{37}$ and receptive needle and syringe sharing persists (over 20\% of PWID reported sharing at least once in the last 6 months) ${ }^{38}$ Approximately $46 \%$ of the province's population and over $80 \%$ of PWID are low income and covered by the provincial drug insurance programme. ${ }^{39}$ Unlike the closely studied Vancouver population, which is concentrated in the Downtown Eastside, Montréal's PWID population is geographically scattered. ${ }^{40}$ Finally, although approximately half of the PWID population prefers to inject drugs other than opioids, ${ }^{41}$ the risk of fatal drug overdose is increasing as drug preferences shift to opioids and fentanyl contaminates local drug supplies. ${ }^{3742}$

\section{Study design and study population}

We will develop an open cohort of PWID in Québec. Adults ( $\geq 18$ years of age) living in the province with a medical visit or hospitalisation for injection drug use during the 12-year study period (1 January 2009 to 31 December 2020, inclusive) will be enrolled and remain in the cohort for as long as the Régie de l'assurance maladie $d u$ Québec (RAMQ) records them living in the province. For each person identified this way, we will extract all health 
Table 1 Administrative health data available via les centres d'accès aux données de recherche de l'Institut de la statistique du Québec ${ }^{29}$

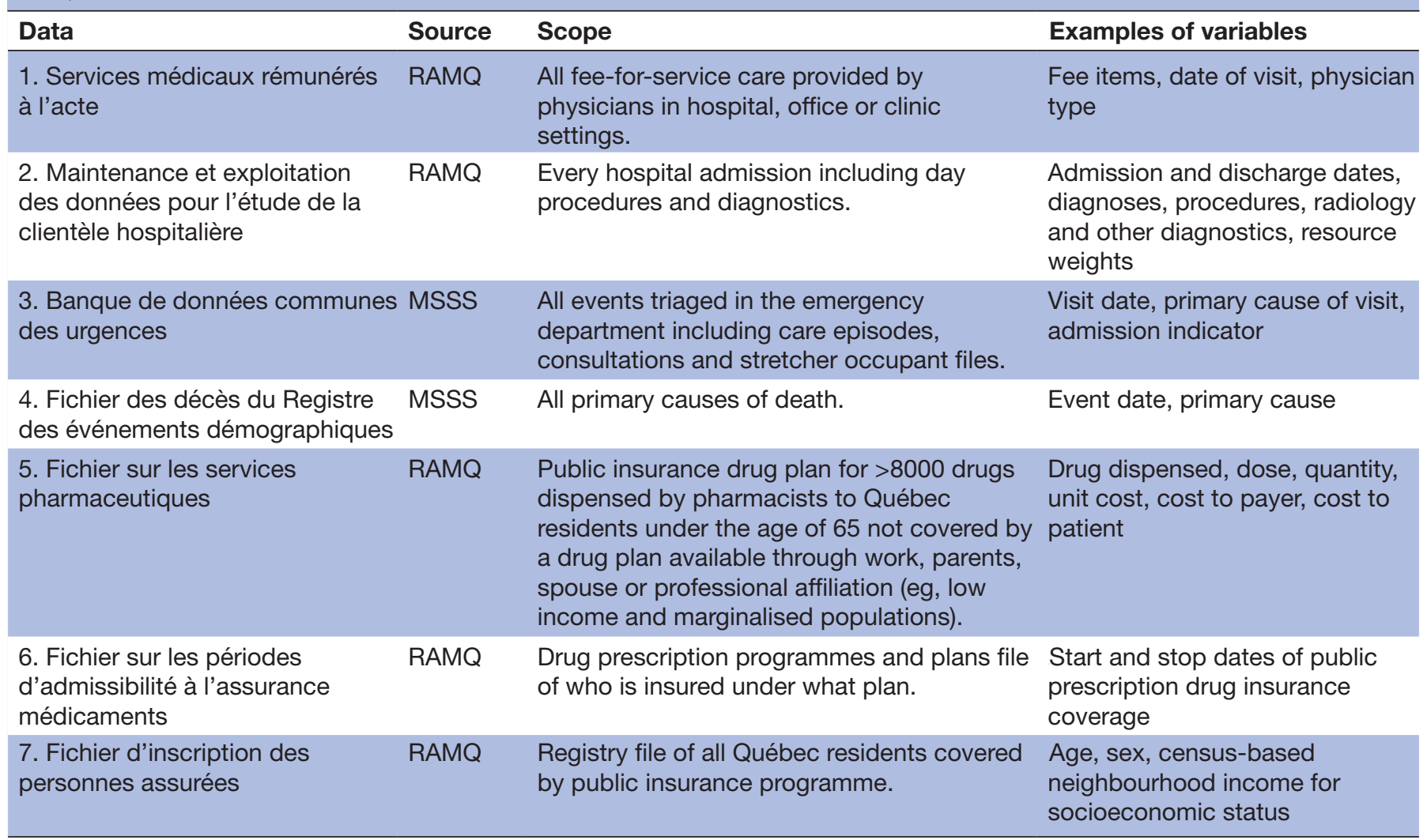

MSSS, Ministère de la Santé et des Services sociaux; RAMQ, Régie de l'assurance maladie du Québec.

service use records over the entire study period. These data will be used to disentangle the effects of Montréalspecific interventions from province-wide and nationwide policies, determine the costs of health service use per sequela, and estimate incidence, prevalence and time to sequelae and death.

\section{Data sources and linkages}

A validated coding algorithm will be applied to vital statistics and health administrative data sets (table 1) to construct the cohort. ${ }^{43}$ Physician claims, hospital admissions, emergency department visit records, mortality and public prescription drug plan data contain the information needed to identify PWID who have received medical care, pharmaceutical treatment or died from injectionrelated injuries or illnesses. They also serve to describe health service use. The public prescription drug plan and drug prescription programme files capture drug coverage and dispensing details, and the registered persons file provides key demographic information for stratified analysis and control of confounders (eg, age, sex and socioeconomic status). This data will be complemented with non-linkable data from: (i) Urgences-Santé for all paramedic dispatches for suspected overdose or intoxication (call 23); (ii) the Centres d'accès au matériel d'injection for regional monthly dispensation data of all needle and syringe paraphernalia and (iii) l'Institut national de santé publique du Québec's (INSPQ) Surveillance des maladies infectieuses chez les Utilisateurs de Drogues par Injection (SurvUDI) repeated cross-sectional biobehavioural surveys of PWID for parameter estimation.

Parameters that cannot be estimated directly from these local data sources will be extracted from relevant published material (eg, peer-reviewed and grey literature).

\section{Analysis plan for each objective}

We will use epidemiologic methods to estimate the risk of each sequela and death; and a variety of econometric and mathematical modelling methods to quantify the population-level effects of harm reduction interventions on these outcomes (table 2). Our null hypothesis for each intervention is that they have no effect on counts of sequelae or deaths. Data will be prepared using SAS (V.9.4) and statistical analyses will be performed using $\mathrm{R}$ (V.3.2.5 or higher).

Data quality for the administrative data sets (table 1) is exceptionally high. A recent audit by the Canadian Institute for Health Information found of 835399 Quebec acute care admissions for fiscal year 2017-2018 only 5 and 16 records were missing discharge disposition and most responsible diagnosis information, respectively, and only three records of 368364 day surgeries were missing most responsible diagnosis. ${ }^{44}$ As such, where administrative 
Table 2 Summary of methods that will be used to evaluate the effects of interventions on outcomes

\begin{tabular}{|c|c|c|c|}
\hline Intervention & Outcome & Method & Data \\
\hline \multirow[t]{2}{*}{$\begin{array}{l}\text { Supervised injection facility } \\
\text { (June 2017) }\end{array}$} & $\begin{array}{l}\text { SSTVIs } \\
\text { Overdose } \\
\text { Anoxic/toxicity-related brain } \\
\text { injury } \\
\text { Death }\end{array}$ & $\begin{array}{l}\text { Interrupted time series and } \\
\text { segmented regression }\end{array}$ & $\begin{array}{l}\text { Linked administrative health data } \\
(1 / 2009 \text { to } 12 / 2020)\end{array}$ \\
\hline & $\begin{array}{l}\text { HIV } \\
\text { HCV }\end{array}$ & $\begin{array}{l}\text { Mathematical modelling (see } \\
\text { Objective 3) }\end{array}$ & $\begin{array}{l}\text { Linked administrative health data; } \\
\text { Centres d'accès au materiel d'injection } \\
\text { dispensations ( } 1 / 2009 \text { to } 12 / 2020) ; \\
\text { INSPQ's SurvUDI (2006/2007 to } \\
2019 / 2020 \text { cycles) }\end{array}$ \\
\hline $\begin{array}{l}\text { Needle and syringe program } \\
\text { (1989) }\end{array}$ & SSTVIs & $\begin{array}{l}\text { Poisson or negative binomial } \\
\text { regression models }\end{array}$ & $\begin{array}{l}\text { Linked administrative health data; } \\
\text { Centres d'accès au materiel d'injection } \\
\text { dispensations }\end{array}$ \\
\hline \multirow[t]{2}{*}{ Opioid agonist therapy } & $\begin{array}{l}\text { SSTVIs } \\
\text { Overdose } \\
\text { Anoxic/toxicity-related brain } \\
\text { injury } \\
\text { Death }\end{array}$ & $\begin{array}{l}\text { Marginal structural Cox models; } \\
\text { Missing cause approach (section } \\
\text { 2.3.1) }\end{array}$ & Linked administrative health data \\
\hline & $\begin{array}{l}\text { HIV } \\
\mathrm{HCV}\end{array}$ & Mathematical modelling & $\begin{array}{l}\text { Linked administrative health data; } \\
\text { Centres d'accès au materiel d'injection } \\
\text { dispensations; } \\
\text { INSPQ's SurvUDI }\end{array}$ \\
\hline $\begin{array}{l}\text { Paramedic's use of naloxone; } \\
\text { Good Samaritan Drug Overdose } \\
\text { Act }\end{array}$ & $\begin{array}{l}\text { Anoxic/toxicity-related brain } \\
\text { injury } \\
\text { Death }\end{array}$ & $\begin{array}{l}\text { Interrupted time series and } \\
\text { segmented regression }\end{array}$ & $\begin{array}{l}\text { Linked administrative health data; } \\
\text { Urgences-Santé paramedic dispatches } \\
(1 / 2012 \text { to } 12 / 2018)\end{array}$ \\
\hline
\end{tabular}

HCV, hepatitis C virus; INSPQ, l'Institut national de santé publique du Québec; SSTVIs, skin, soft tissue and vascular infections; SurvUDI,

Surveillance des maladies infectieuses chez les Utilisateurs de Drogues par Injection

records are missing pertinent information, they will be excluded from analyses and the number of observations omitted due to missing data will be documented. Conversely, for the biobehavioural surveys, paramedic data and counts of equipment distributed, we will use imputation methods and report the method and extent.

Where appropriate, we will stratify results by sex and age. Age categories will be empirically determined and will reflect differences in health risk and service use patterns. Notably, race-based data are not available for this study.

Results will be reported using appropriate Enhancing the QUAlity and Transparency Of Health Research guidelines (eg, Strengthening the Reporting of Observational Studies in Epidemiology, Preferred Reporting Items for Systematic Reviews and Meta-Analyses, and Consolidated Health Economic Evaluation Reporting Standards) and will include both p-values and 95\% CIs.

\section{Estimating instantaneous rates of sequelae occurrence}

We will use competing risk models to estimate local instantaneous rates of occurrence of diagnosed injectionrelated injuries and infections (henceforth 'sequelae'). ${ }^{45}$ These models estimate the marginal probability of each competing event (sequela) using the cumulative incidence function (based on, for example, the LunnMcNeil approach and its flexible extensions).$^{46}$ The eventspecific cumulative incidence function will determine the instantaneous risk of occurrence for each sequela while incorporating the effects of confounders on the risk of event occurrence and accounting for competing risks. ${ }^{45}$ For the purposes of the CEA, this method enables us to better simulate the health trajectories of PWID, given the high prevalence of multiple comorbidities and their demonstrated effects on disease progression rates (eg, HIV/HCV coinfection). ${ }^{47} 48$ To test the proportional hazards assumption and, if rejected, model the timedependent effects of confounders, we will use the flexible spline-based extension of the Lunn-McNeil competing risks model, proposed and validated by members of our team. ${ }^{49}$ If the proportional hazards hypothesis is rejected, the event-specific cumulative incidence curves, conditional on time-dependent effects, will be estimated using our flexible model. ${ }^{50}$

\section{Determining the costs of treating sequelae and interventions}

We will estimate out-of-hospital and emergency department costs for treating each sequela using physician claims. Costs of in-patient and day-case hospitalisations will be calculated using the province's relative resource 
intensity weight assigned to each admission multiplied by the average cost per unit for each fiscal year as provided by the Ministère de la santé et des services sociaux. ${ }^{51}$ Prescription drug costs will be tabulated from the public insurance and claims administrative data sets; while a fixed cost per paramedic-attended event will apply.

We will use multivariable generalised linear mixed models to estimate mean marginal costs of treating each sequela accounting for interdependence between repeated measures ${ }^{52}$ and addressing skewness, heteroscedasticity and excess zeros common in costing data. ${ }^{53}$ We will use modified Park tests to assess the extent of heteroscedasticity and identify appropriate distributional families. ${ }^{54}$

Costs of services rendered at SIFs and NSPs will be restricted to programme operating costs estimated from annual reports and pharmaceutical data, respectively. We will not include programme start-up costs as we will be working from the perspective that all interventions are already available. All costs will be adjusted for inflation using the general Canadian Consumer Price Index. ${ }^{55} 56$

\section{Estimating the effect sizes of each harm reduction intervention}

To estimate the population-level effects of the newly implemented SIFs, we will use an interrupted time series design. ${ }^{57-59}$ The balanced time series will have 10 quarterly study intervals before (December 2014 to May 2017, inclusive) and after the implementation of the SIFs (July 2017 to December 2019, inclusive). The time series will be centred on June 2017 when the first three sites were implemented, consider the implementation of the final SIF (November 2017) as scale-up, and end before COVID19-related service disruptions began (March 2020). ${ }^{60} \mathrm{We}$ will use segmented regression with a time series specification and autoregressive error models to test the effects of SIFs separately on SSTVIs, overdose, anoxic/ toxicity-related brain injury and death (see table 2 for a summary of methods to estimate effect sizes of interventions on sequelae, and data sources to be used). We will use the two-sided Durbin-Watson test, plot of residuals and autocorrelation plots to detect autocorrelation (eg, first order) and moving averages. Where needed, we will adjust standard errors using the Newey-West approach and add effect lags to models. ${ }^{32}$

NSPs were first introduced in Montréal in 1989-well before the earliest year for which administrative health data is available (1995). As such, we will use Poisson or (if warranted) negative binomial regression models to assess the association between aggregated monthly counts of equipment distributed and the incidence of SSTVIs for PWID in Montréal. Seasonality, budget constraints and service expansions and contractions are all factors that affect the number of needles, syringes and other equipment dispensed. ${ }^{41-63}$ To determine which of the two model types (Poisson or negative binomial) is more consistent with our data, we will use Pearson $\chi^{2}$ dispersion statistics and residual plots. ${ }^{64} 65$ Lags between the number of syringes distributed and the incidence of health outcomes will be estimated using the weighted cumulative exposure approach ${ }^{66-68}$ and informed by expert input. ${ }^{6970}$ Flexible-weighted cumulative exposure modelling will also help assess the relative impact of the frequency of syringes distributed at different lags. ${ }^{6-68}$

To estimate the effect size of OAT on overdose, SSTVIs, anoxic/toxicity-related brain injury and death, we will use marginal structural Cox models and restrict our analysis to PWID registered with the province's public drug insurance programme. These models use time-varying inverse-probability of treatment weighting at each time point to create a 'pseudo-population' of PWID in which subjects with different exposure patterns have similar distributions of time-varying confounders or mediators. ${ }^{71}$ For our purposes, OAT initiation will be defined as a new OAT prescription dispensed with no indication of OAT treatment in the previous 2 years (wash-in period subject to change based on expert feedback). Treatment cessation will be defined as any prescription with more than 30-days since last dispensation, with the potential for reinitiation any time thereafter. ${ }^{73}$ To account for the possibility of residual confounding by some unmeasured risk factors potentially associated with OAT, we will carry out sensitivity analyses using the 'missing cause' approach which corrects the estimates for an interaction between exposure (OAT) and the discrepancy between observed versus predicted exposure. Developed by members of our team, the method has been found in simulations to yield more stable estimates than other traditional methods (eg, instrumental variable approach). ${ }^{74}$

We will evaluate the effects of paramedics' use of naloxone and the Good Samaritan Drug Overdose Act on rates of overdose and overdose-related deaths using interrupted time series. For the provision of naloxone by paramedics we will use 11 quarters preimplementation (October 2011-June 2014), during scale-up (July 2014-March 2017) and postimplementation (April 2017December 2019), each. For the Good Samaritan Drug Overdose Act, we will focus on 11 quarters each preimplementation (August 2014-April 2017) and postimplementation (June 2017-February 2020).

\section{Constructing our mathematical model}

We will construct a stochastic individual-based model to quantify the public health and economic impacts of our interventions (a) together (current scenario), (b) individually and (c) under simulated conditions of full-scale up while accounting for the unique epidemiological profile and health service use patterns of Montréal's PWID population. We selected the stochastic individual model as our mathematical framework because it allows us to update individuals' risk of outcomes as relevant attributes (eg, individuals' characteristics, the setting and other environmental features) change over time. ${ }^{75}$ The development and implementation of the model will adhere strictly to the International Society for Pharmacoeconomics and Outcomes Research's (ISPOR) and Society for Medical Decision Making 
guidelines on model development, application, transparency and validation. ${ }^{76-79}$ We will incorporate Philips et als minimal set of conditions to ensure sound model development with respect to structure, data and consistency. ${ }^{80}$ To justify structural assumptions (ie, face-validity) and ensure we accurately simulate patient trajectories, we will amalgamate existing disease-specific models ${ }^{81} 82$ and incorporate patient and clinician expert feedback in the development of our model. Treatment decisions will be developed from 'if-then' statements based on published standards of care, treatment guidelines and clinicians' input.

The model will be populated using results from our empirical analyses estimating risks of injection-related infections, injuries and deaths and intervention effect sizes to simulate infections and injuries in a hypothetical population of PWID in Montréal. Where necessary, these data will be supplemented with surveillance data and published sources (eg, meta-analyses, clinical studies) for parameters such as forces of infection for HIV and HCV (likely constant) and interactions between agents. ${ }^{83}$ To validate the model's consistency, the simulation will run through a series of test scenarios to ensure outcomes observed match those expected. The finalised model will estimate the individual, synergistic and cumulative effects of the interventions on PWID living in Montréal over a 40-year time horizon. ${ }^{84}$

\section{Conducting the cost-effectiveness analysis}

Costs and outcomes will be discounted to reflect time preferences using standard accepted methods (recommended rate of $1.5 \%$, with $0 \%-3 \%$ used in sensitivity analyses) ${ }^{56}$ Incremental cost-effectiveness ratios (ICERs) will summarise the health gains versus costs of interventions relative to our base case (no harm reduction interventions).

Although quality adjusted life years (QALYs) are regularly used as an aggregate, single metric of longevity and health-related quality of life in CEA, for our purposes, relevant utility estimates do not exist for all our sequelae. For those that do exist, there are several challenges related to the use of QALYs which limit their usefulness here. For example, the different tools used to estimate QALYs can yield significantly different values. Furthermore, quality of life information from persons with lived experience are not always available; and particular to patients with brain injury difficult to impossible to ascertain. Finally, QALYs favour treatable illnesses over incremental improvements for chronic conditions. ${ }^{85}$ For these reasons, we are electing to report ICERs using deaths averted with secondary analysis focusing on SSTVIs averted. ${ }^{86}$ We will conduct probabilistic sensitivity analysis, plot the efficiency frontier for combinations of harm reduction interventions and include cost-effectiveness acceptability curves to summarise the impact of uncertainty on willingness to pay on our results.

\section{Patient and public involvement}

We will recruit two patient-partners with lived experience through our networks at INSPQ and the McGill Centre for Viral Diseases to provide expert feedback on health seeking behaviour and self-treatment of infections and injuries, and to review our model design for the accurate representation of pathways PWID can encounter. As this project uses secondary administrative data and previously collected biobehavioural surveys, no additional patients will be recruited for the conduct of the study.

\section{ETHICS AND DISSEMINATION}

This study will rely solely on the analysis of secondary de-identified administrative health, surveillance and programme data supplemented with peer-reviewed and grey literature. There will be no recruitment of participants for additional data, and results will be reported at the aggregate level only. All members of the research team who will have access to the data have had the necessary tri-council privacy training. The study received ethical approval from McGill University's Institutional Review Board (Study Number: A08-E53-19B).

Our project will culminate in a publicly accessible report and op-ed, and results will be published in open access peer-reviewed journals and presented at scientific conferences. Although data will not be shareable, we will make our code available in a public repository.

\section{DISCUSSION}

Despite the significant investments in harm reduction and the unique epidemiological profile of Montréal's PWID population, reports exploring the impacts of interventions are sparse. Meanwhile, most CEAs of harm reduction interventions for PWID have neglected the common and/or potentially costly consequences of SSTVIs and anoxic/toxicity-related brain injury. Our comprehensive analysis will fill in critical gaps on disease burden and health service utilisation by including a detailed investigation of the epidemiology of these sequelae and will provide new evidence on the cost-effectiveness (including potentially, cost-saving effects) of combinations of the target harm reduction interventions. Unique contributions from this project include characterising the demographics, disease burden and health service needs of Montréal's PWID, describing the disease progression for neglected injection drug use-related sequelae, and developing a calibrated simulation model that can be used to estimate the effects of future policy scenarios.

The primary challenge for this project is the construction of a parsimonious but accurate model of health trajectories for PWID in Montréal. To this end, several assumptions about the population will need to be made including the duration of injection drug use (eg, the 'length of the injecting career', and periodicity), the injecting risk behaviour (ie, frequency of injecting, sharing of equipment and characteristics of networks) 
and transmissibility of infectious diseases (eg, HIV, HCV and pathogens that cause skin, soft tissue and vascular infections including amyloid A amyloidosis). ${ }^{1387} 88$ Although we will have access to biobehavioural surveys to inform these parameters, the illicit nature and stigmatisation of injection drug use means we will likely underestimate values. By working with clinician and peer experts, and calibrating our model to observed outcomes in our administrative data, we aim to minimise the effects of such assumptions on our model's accuracy.

A related challenge is the use of administrative health data to identify and describe the PWID cohort. This method of capturing the cohort is dependent on healthcare access and utilisation patterns of PWID, and the quality of data available. In settings without comprehensive records of service use or where access to services and treatment is restricted, this approach can lead to under-ascertainment and estimation of PWID populations; overestimating incidence of infections relative to the PWID population and undercounting overdose events treated in the community. ${ }^{89}$ Reliance on administrative data for accurate diagnosis of injection drug use may lead to misclassification. By working with data in a setting where health services and pharmaceuticals are provided at little to no cost to PWID, applying modern surveillance methods and using validated algorithms, we will mitigate the potential for misclassification, capture as many adverse events as possible outside of a strict longitudinal cohort study and focus our analyses on the effectiveness of interventions among PWID who interact with the healthcare system. ${ }^{4189} 90$

Concomitantly, there will be limitations to our evaluations of the harm reduction interventions included in this CEA. We will not be able to stratify effect sizes for all interventions by sex and age owing to limitations in statistical power. Extensive model calibration will ensure assumptions on the effectiveness of interventions for different sub-groups best reflect the reality of PWID living in Montréal.

Further, we cannot estimate the effect of community naloxone distribution, directly. We are aware that in November 2017, 1900 pharmacies across Quebec began offering naloxone kits freely to residents 14 years or older with a provincial health insurance $\operatorname{card}^{91-93}$ and that 15 Montréal community-based groups (including Cactus, Dopamine, Spectre de rue and L'Anonyme), successfully lobbied the provincial government to begin distributing naloxone kits freely and anonymously in May 2018. ${ }^{91-93}$ While public reports reveal 1831 kits were distributed in 2017, 7541 in 2018 and 13268 in 2019 across the whole province, ${ }^{91} 94$ more granular data including the purpose of replacement (ie, kit expired, was lost/stollen, was used), estimates of overdose events revived or demographics of peers equipped with kits are not available. We are working with partners at INSPQ and the SIFs to understand the data available to us, and where possible, will include counts of kits distributed as part of the evaluation of SIFs.
Given that model parameters will be estimated using Montréal-specific administrative health data supplemented with surveillance data, and from published literature, and because we are dealing with a heterogeneous population, there will be some parameter uncertainty in the model. To compensate for this, we will carefully select controls (eg, propensity score matched geographically unexposed individuals) ${ }^{95}$ and conduct comprehensive sensitivity analyses at all stages of model development including parameter ascertainment. Approaches will include restricting analyses to individuals with fixed addresses for geographic analyses on the effects of interventions based on proximity to services; ${ }^{96}$ conducting probabilistic sensitivity analyses and producing costeffectiveness acceptability curves to summarise the uncertainty in the estimates of the CEA.

Our comprehensive study will equip health services planners with much-needed information to optimise harm reduction interventions in resource constrained settings locally and internationally. While the results will be specific to a Canadian city, by focusing on Montréal's understudied and diverse PWID population and incorporating otherwise neglected injection-drug use sequelae, this project will extend the generalisability and relevance of the existing harm reduction literature. Our results will be of international interest, as injection-related illnesses continue to rise (eg, opioid epidemics) ${ }^{97} 98$ and communities explore harm reduction options.

\section{Author affiliations}

${ }^{1}$ Department of Epidemiology, Biostatistics and Occupational Health, School of Population and Global Health, McGill University, Montréal, Québec, Canada ${ }^{2}$ Research Institute, McGill University Health Centre, Montréal, Québec, Canada ${ }^{3}$ Clinical and Health Informatics Research Group, Department of Medicine, McGill University, Montréal, Québec, Canada

${ }^{4}$ Evidera, Boston, Massachusetts, USA

${ }^{5}$ London School of Economics and Political Science, London, UK

${ }^{6}$ Douglas Research Institute, Montréal, Québec, Canada

${ }^{7}$ Department of Psychiatry, McGill University, Montréal, Québec, Canada

${ }^{8}$ Department of Economics, McGill University, Montréal, Québec, Canada

Contributors DP is the principal investigator of the study. DP conceived the study and overall design, with critical revisions from MA, DLB, JJC, EL, MM-G and ECS. All coauthors developed the analysis plan, with specific methodological input from MA, JJC, EL and MM-G. DP drafted the manuscript. All authors provided feedback on the manuscript, approved the final version to be published and agreed to be accountable to all aspects of the work ensuring the project's accuracy and integrity.

Funding This work is supported by the Canadian Institutes of Health Research (ClHR), Project Grant programme, grant number 436351 (principal investigator: DP). DP is also supported by a Junior 1 Research Scholar Award from the Fonds de recherche du Québec-Santé.

Competing interests None declared.

Patient and public involvement Patients and/or the public were involved in the design, or conduct, or reporting or dissemination plans of this research. Refer to the Methods section for further details.

Patient consent for publication Not applicable.

Provenance and peer review Not commissioned; externally peer reviewed.

Open access This is an open access article distributed in accordance with the Creative Commons Attribution Non Commercial (CC BY-NC 4.0) license, which permits others to distribute, remix, adapt, build upon this work non-commercially, and license their derivative works on different terms, provided the original work is 
properly cited, appropriate credit is given, any changes made indicated, and the use is non-commercial. See: http://creativecommons.org/licenses/by-nc/4.0/.

ORCID iD

Dimitra Panagiotoglou http://orcid.org/0000-0002-6175-3634

\section{REFERENCES}

1 Riley D, Pates R, Monaghan G, et al. A brief history of harm reduction. In: Pates $\mathrm{R}$, Riley D, eds. Harm reduction in substance use and high-risk behaviour: international policy and practice. Oxford, UK: Wiley-Blackwell, 2012.

2 Marshall BDL, Milloy M-J, Wood E, et al. Reduction in overdose mortality after the opening of North America's first medically supervised safer injecting facility: a retrospective population-based study. Lancet 2011;377:1429-37.

3 Bayoumi AM, Zaric GS. The cost-effectiveness of Vancouver's supervised injection facility. CMAJ 2008;179:1143-51.

4 Macneil J, Pauly B. Impact: a case study examining the closure of a large urban fixed site needle exchange in Canada. Harm Reduct $J$ 2010;7:11.

5 Potier C, Laprévote V, Dubois-Arber F, et al. Supervised injection services: what has been demonstrated? A systematic literature review. Drug Alcohol Depend 2014;145:48-68.

6 Ruiz MS, O'Rourke A, Allen ST. Impact evaluation of a policy intervention for HIV prevention in Washington, DC. AIDS Behav 2016;20:22-8.

7 Salmon AM, van Beek I, Amin J, et al. The impact of a supervised injecting facility on ambulance call-outs in Sydney, Australia. Addiction 2010;105:678-83.

8 Aspinall EJ, Nambiar D, Goldberg DJ, et al. Are needle and syringe programmes associated with a reduction in HIV transmission among people who inject drugs: a systematic review and meta-analysis. Int $J$ Epidemiol 2014;43:235-48.

9 CBC News. Visits to Montreal's supervised injection sites more than doubled in first year. Montreal, QC: CBC News, 2018.

10 Dietze P, Winter R, Pedrana A, et al. Mobile safe injecting facilities in Barcelona and Berlin. Int J Drug Policy 2012;23:257-60.

11 Hope VD, Marongiu A, Parry JV, et al. The extent of injection site infection in injecting drug users: findings from a national surveillance study. Epidemiol Infect 2010;138:1510-8.

12 Larney S, Peacock A, Mathers BM, et al. A systematic review of injecting-related injury and disease among people who inject drugs. Drug Alcohol Depend 2017;171:39-49.

13 Harris M, Brathwaite R, McGowan CR, et al. 'Care and prevent': rationale for investigating skin and soft tissue infections and $A A$ amyloidosis among people who inject drugs in London. Harm Reduct J 2018;15:23.

14 Pieper B, Kirsner RS, Templin TN, et al. Injection drug use: an understudied cause of venous disease. Arch Dermatol 2007;143:1305-9.

15 Cooper HLF, Brady JE, Ciccarone D, et al. Nationwide increase in the number of hospitalizations for illicit injection drug use-related infective endocarditis. Clin Infect Dis 2007;45:1200-3.

16 Irish C, Maxwell R, Dancox M, et al. Skin and soft tissue infections and vascular disease among drug users, England. Emerg Infect Dis 2007:13:1510-1.

17 Connolly JO, Gillmore JD, Lachmann HJ, et al. Renal amyloidosis in intravenous drug users. QJM 2006;99:737-42.

18 Andresen MA, Boyd N. A cost-benefit and cost-effectiveness analysis of Vancouver's supervised injection facility. Int J Drug Policy 2010;21:70-6.

19 Clark HW. Even non-fatal overdoses can lead to severe consequences. (SAMHSA center for substance abuse treatment, 2014).

20 O'Brien P, Todd J. Hypoxic brain injury following heroin overdose. Brain Impairment 2009;10:169-79.

21 Andersen SN, Skullerud K. Hypoxic/ischaemic brain damage, especially pallidal lesions, in heroin addicts. Forensic Sci Int 1999;102:51-9.

22 Guy GP, Pasalic E, Zhang K. Emergency department visits involving opioid overdoses, U.S., 2010-2014. Am J Prev Med 2018;54:e37-9.

23 Hasegawa K, Brown DFM, Tsugawa Y, et al. Epidemiology of emergency department visits for opioid overdose: a populationbased study. Mayo Clin Proc 2014;89:462-71.

24 Leclerc $P$, Vandal AC, Fall A, et al. Estimating the size of the population of persons who inject drugs in the island of Montreal, Canada, using a six-source capture-recapture model. Drug Alcohol Depend 2014;142:174-80.
25 Hankins C, Gendron S, Bruneau J. Evaluating Montreal's needle exchange CACTUS-Montreal. Washington, DC, 1994.

26 Government of Canada. Supervised consumption sites: status of applications, 2018.

27 Canadian Press. Monteral police intervene in double overdose near downtown Metro. in Montreal Gazette. Montreal, QC: Postmedia, 2017.

28 Régie de l'assurance maladie du Québec. Prescription drug insurance, 2018.

29 Régie de l'assurance maladie du Québec. List of medications, 2018.

30 Peterson S \& d'Entremont PE. Hiv prevention pill could save health care dollars. CBC news, 2016.

31 HIV Clinic. Access and coverage of antiretroviral drugs through Canada's provincial and territorial drug programs, 2018.

32 Régie de l'assurance maladie du Québec. Program for free access to naloxone. Vol. 2020. Quebec City, Quebec, 2017.

33 Sciences G, I. Quebec expands patient access to chronic hepatitis C therapies. Newswire, 2018.

34 Centre and association for people living with Hepatitis C (CAPAHC). Quebec reaches a major milestone in the treatment of Hepatitis $C$ Harvoni and Holkira Pak are now covered by the public drug plan. in newswire, 2015.

35 Government of Canada. About the good Samaritan drug overdose act. Ottawa, ON: Government of Canada, 2018.

36 Bruneau J, Roy E, Arruda N, et al. The rising prevalence of prescription opioid injection and its association with hepatitis $\mathrm{C}$ incidence among street-drug users. Addiction 2012;107:1318-27.

37 Morris MD, Shiboski S, Bruneau J, et al. Geographic differences in temporal incidence trends of hepatitis $C$ virus infection among people who inject drugs: the InC3 collaboration. Clin Infect Dis 2017:64:860-9.

38 Perrault M, Archambault L. Requis de services en matière de traitement des troubles liés l'usage d'opioïdes sur l'île de Montréal. Narcomanes, I.C.d.R.e.d.A.p. Centre intégré universitaire de santé et de services sociaux de l'Est-de-l'île-de-Montréal, and Centre de recherche et d'aide pour narcomanes (CRAN), 2017.

39 Régie de l'assurance maladie du Québec. The RAMQ in a few figures, 2020.

40 Green T HC, Palmer D, Boivin J-F, et al. Ascertaining the need for a supervised injection facility (SIF): the burden of public injecting in Montreal, Canada. Journal of Drug Issues 2003:33.

41 Centre d'expertise et de reference en sante publique. Reseau SurvUDI 1995-2016: infections PAR Le VIH et PAR Le VHC CheZ les personnes UDI. Institut national de sante publique (INSPQ), 2018.

42 Lindeman T. Rash of fatal overdoses in Montreal could be linked to fentanyl. CBC News, 2014.

43 Janjua NZ, Islam N, Kuo M, et al. Identifying injection drug use and estimating population size of people who inject drugs using healthcare administrative datasets. Int J Drug Policy 2018;55:31-9.

44 Canadian Institute for Health Information. Data quality documentation: Hospital morbidity database: current year information 2017-2018. Ottawa, ON: CIHI, 2019.

45 Austin PC, Lee DS, Fine JP. Introduction to the analysis of survival data in the presence of competing risks. Circulation 2016;133:601-9.

46 Lunn M, McNeil D. Applying COX regression to competing risks. Biometrics 1995;51:524-32.

47 Thein $\mathrm{H}-\mathrm{H}$, Yi Q, Dore GJ, et al. Estimation of stage-specific fibrosis progression rates in chronic hepatitis $\mathrm{C}$ virus infection: a metaanalysis and meta-regression. Hepatology 2008;48:418-31.

48 Thein $\mathrm{H}-\mathrm{H}, \mathrm{Yi}$ Q, Dore GJ, et al. Natural history of hepatitis $\mathrm{C}$ virus infection in HIV-infected individuals and the impact of HIV in the era of highly active antiretroviral therapy: a meta-analysis. AIDS 2008;22:1979-91.

49 Belot A, Abrahamowicz M, Remontet L, et al. Flexible modeling of competing risks in survival analysis. Stat Med 2010;29:2453-68.

50 Wynant W, Abrahamowicz M. Flexible estimation of survival curves conditional on non-linear and time-dependent predictor effects. Stat Med 2016;35:553-65.

51 Strumpf E, Ammi M, Diop M, et al. The impact of team-based primary care on health care services utilization and costs: Quebec's family medicine groups. J Health Econ 2017;55:76-94.

52 Gebregziabher M, Zhao Y, Dismuke CE, et al. Joint modeling of multiple longitudinal cost outcomes using multivariate generalized linear mixed models. Health Serv Outcomes Res Methodol 2013:13:39-57.

53 Liu L, Strawderman RL, Cowen ME, et al. A flexible two-part random effects model for correlated medical costs. $J$ Health Econ 2010;29:110-23

54 Barber J, Thompson S. Multiple regression of cost data: use of generalised linear models. J Health Serv Res Policy 2004;9:197-204. 
55 Statistics Canada. Canadian alcohol, tobacco and drugs: 2017 summary, 2019.

56 CADTH. Guidelines for the economic evaluation of health technologies: Canada, 2017.

57 Lopez Bernal J, Cummins S, Gasparrini A. The use of controls in interrupted time series studies of public health interventions. Int $J$ Epidemiol 2018;47:2082-93.

58 Linden A. Combining synthetic controls and interrupted time series analysis to improve causal inference in program evaluation. $J$ Eval Clin Pract 2018;24:447-53.

59 Ryan AM, Krinsky S, Kontopantelis E, et al. Long-Term evidence for the effect of pay-for-performance in primary care on mortality in the UK: a population study. Lancet 2016;388:268-74.

60 Penfold RB, Zhang F. Use of interrupted time series analysis in evaluating health care quality improvements. Acad Pediatr 2013;13:S38-44.

61 Duplessy C, Reynaud EG. Long-Term survey of a syringe-dispensing machine needle exchange program: answering public concerns. Harm Reduct $J$ 2014;11:16.

62 The Concordian. Needle exchange program cut from heads and hands. in the Concordian. Montreal, QC, 2011.

63 Kovac A. Needle point and counter point: local injection site to open after syringe exchange closure. Montreal, QC: The Link, 2011.

64 Meyer J. Poisson or negative binomial? Using count model diagnostics to select model. in the analysis factor, 2018.

65 Liu W, Cela J. Count data in SAS. SAS Institute Statistics and Data Analysis, 2008.

66 Sylvestre M-P, Abrahamowicz M. Flexible modeling of the cumulative effects of time-dependent exposures on the hazard. Stat Med 2009;28:3437-53.

67 Danieli C, Abrahamowicz M. Competing risks modeling of cumulative effects of time-varying drug exposures. Stat Methods Med Res 2019;28:248-62.

68 Xiao Y, Abrahamowicz M, Moodie EEM, et al. Flexible marginal structural models for estimating the cumulative effect of a timedependent treatment on the hazard: reassessing the cardiovascular risks of didanosine treatment in the Swiss HIV cohort study. J Am Stat Assoc 2014;109:455-64.

69 Soyiri IN, Reidpath DD, Sarran C. Forecasting asthma-related hospital admissions in London using negative binomial models. Chron Respir Dis 2013;10:85-94.

70 Briët OJT, Amerasinghe PH, Vounatsou P. Generalized seasonal autoregressive integrated moving average models for count data with application to malaria time series with low case numbers. PLOS One 2013;8:e65761.

71 Williamson T, Ravani P. Marginal structural models in clinical research: when and how to use them? Nephrology Dialysis Transplantation 2017;32:ii84-90.

72 Hernán MA, Brumback BA, Robins JM. Estimating the causal effect of zidovudine on CD4 count with a marginal structural model for repeated measures. Stat Med 2002;21:1689-709.

73 Panagiotoglou D, Krebs E, Min JE, et al. Initiating HCV treatment with direct acting agents in opioid agonist treatment: when to start for people co-infected with HIV? Int J Drug Policy 2017;47:169-76.

74 Abrahamowicz M, Bjerre LM, Beauchamp M-E, et al. The missing cause approach to unmeasured confounding in pharmacoepidemiology. Stat Med 2016;35:1001-16.

75 van Gestel A, Severens JL, Webers CAB, et al. Modeling complex treatment strategies: construction and validation of a discrete event simulation model for glaucoma. Value Health 2010;13:358-67.

76 Weinstein MC, O'Brien B, Hornberger J, et al. Principles of good practice for decision analytic modeling in health-care evaluation: report of the ISPOR Task Force on Good Research Practices-Modeling Studies. Value Health 2003;6:9-17.
77 Husereau D, Drummond M, Petrou S, et al. Consolidated health economic evaluation reporting standards (cheers) statement. Value Health 2013;16:e1-15.

78 Eddy DM, Hollingworth W, Caro JJ, et al. Model transparency and validation. Med Decis Making 2012;32:733-43.

79 Roberts M, Russell LB, Paltiel AD, et al. Conceptualizing a model: a report of the ISPOR-SMDM modeling good research practices task Force-2. Med Decis Making 2012;32:678-89.

80 Philips Z, Bojke L, Sculpher M, et al. Good practice guidelines for decision-analytic modelling in health technology assessment: a review and consolidation of quality assessment. Pharmacoeconomics 2006;24:355-71.

81 Najafzadeh M, Andersson K, Shrank WH, et al. Cost-Effectiveness of novel regimens for the treatment of hepatitis $\mathrm{C}$ virus. Ann Intern Med 2015;162:407-19.

82 Revankar N, Ward AJ, Pelligra CG, et al. Modeling economic implications of alternative treatment strategies for acute bacterial skin and skin structure infections. J Med Econ 2014;17:730-40.

83 Rozhnova G, Anastasaki M, Kretzschmar M. Modelling the dynamics of population viral load measures under HIV treatment as prevention. Infect Dis Model 2018;3:160-70.

84 Caro JJ. Discretely integrated condition event (dice) simulation for pharmacoeconomics. Pharmacoeconomics 2016;34:665-72.

85 Nord E, Daniels N, Kamlet M. QALYs: some challenges. Value Health 2009;12 Suppl 1:S10-15.

86 Tsevat J, Moriates C. Value-Based health care meets costeffectiveness AnalysisValue-Based health care meets costeffectiveness analysis. Ann Intern Med 2018;169:329-32.

87 Scott N, Hellard M, McBryde ES. Modeling hepatitis C virus transmission among people who inject drugs: assumptions, limitations and future challenges. Virulence 2016;7:201-8.

88 Pitcher AB, Borquez A, Skaathun B, et al. Mathematical modeling of hepatitis $C$ virus (HCV) prevention among people who inject drugs: a review of the literature and insights for elimination strategies. $J$ Theor Biol 2019;481:194-201.

89 Unick GJ, Rosenblum D, Mars S, et al. Intertwined epidemics: national demographic trends in hospitalizations for heroin- and opioid-related overdoses, 1993-2009. PLoS One 2013;8:e54496.

90 Lankenau SE, Teti M, Silva K, et al. Initiation into prescription opioid misuse amongst young injection drug users. Int $J$ Drug Policy 2012;23:37-44.

91 Moustaqim-Barrette A, Elton-Marshall T, Leece P. Environmental scan: naloxone access and distribution in Canada. Vancouver: Canadian Research Initiative on Substance Misuse (CRISM), 2019.

92 Lach-Aidelbaum M. Harm reduction agency urges Quebec to get naloxone into hands of more opioid users. Montreal, QC: CBC News, 2019.

93 Centre d'expertise et de reference en sante publique. Historique de l'accès la naloxone au Québec. Institut national de sante publique, 2021.

94 So R, Al Hamarneh Y, Barnes M, et al. The status of naloxone in community pharmacies across Canada. Can Pharm J 2020:153:352-6.

95 Kreif N, Grieve R, Sadique MZ. Statistical methods for costeffectiveness analyses that use observational data: a critical appraisal tool and review of current practice. Health Econ 2013;22:486-500.

96 Panagiotoglou D, Law MR, McGrail K. Effect of hospital closures on acute care outcomes in British Columbia, Canada: an interrupted time series study. Med Care 2017;55:50-6.

97 Coffin PO, Tracy M, Bucciarelli A, et al. Identifying injection drug users at risk of nonfatal overdose. Acad Emerg Med 2007;14:616-23.

98 Mathers BM, Degenhardt L, Ali H, et al. Hiv prevention, treatment, and care services for people who inject drugs: a systematic review of global, regional, and national coverage. Lancet 2010;375:1014-28. 